\section{Category}

Peptide Chemistry

\section{Key words}

solid-phase synthesis

disulfide linkage

peptide

heterodimers

A. K. GALANDE*, A. F. SPATOLA (UNIVERSITY OF LOUISVILLE, USA) Solid-Phase Synthesis of Disulfide Heterodimers of Peptides

Org. Lett. 2003, 5, 3431-3434.

\title{
Conjugation of Two Peptides via Disulfide Linkage
}
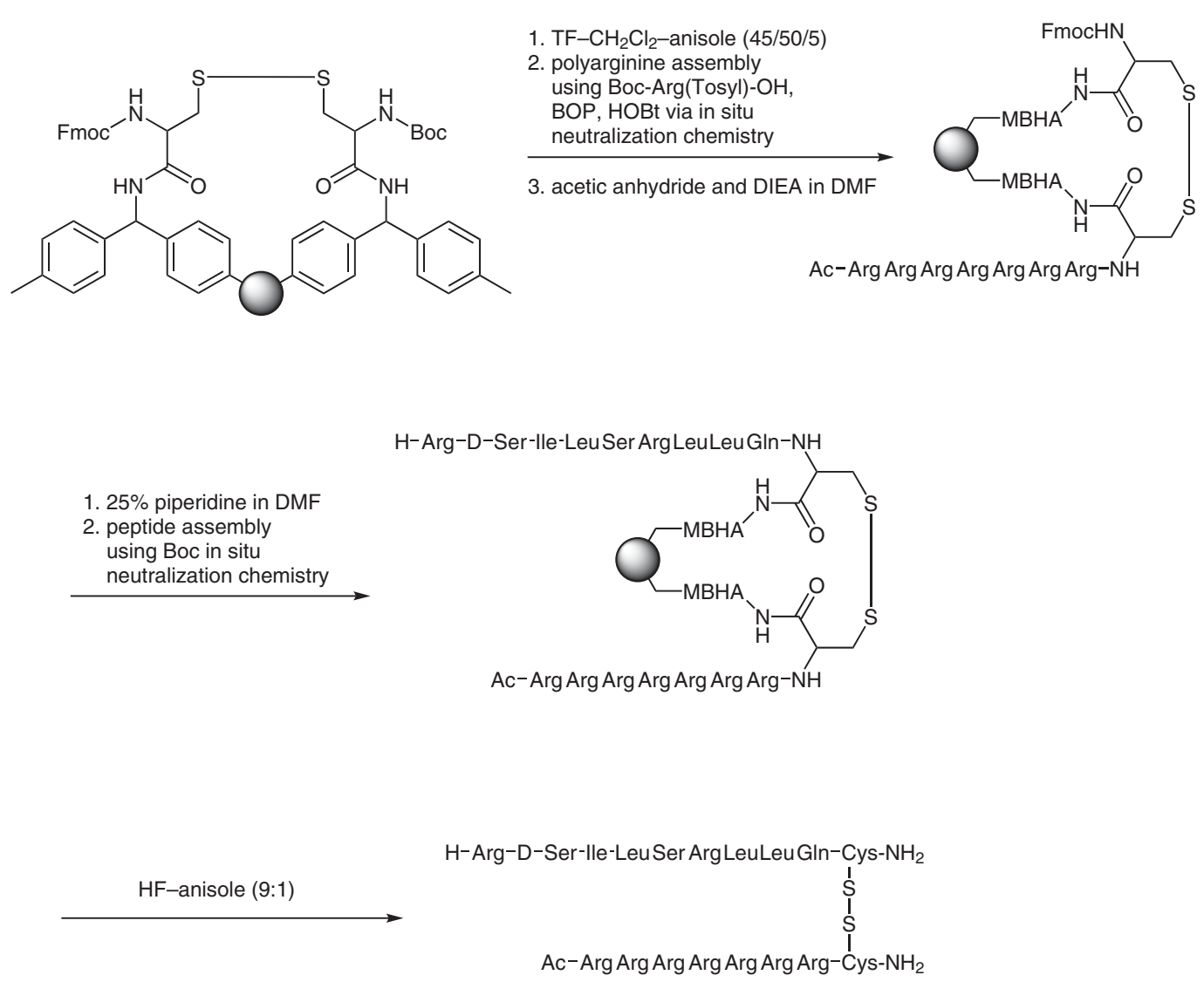

Significance: Nonsymmetric intermolecular disulfide bridges might be advantageous for peptide conjugation in the light of their solubility in a solvent. The authors report an orthogonal disulfide template synthesis, and its application in hydrophobic cell-penetrating peptides.
Comment: The disulfide template could be conjugated with a hepta-arginine segment and LXXLmotif-containing peptides by using such coupling reagents as BOP or HOBt. After the cleavage of the resin from the peptides, polypeptides containing two kinds of peptides conjugated through a disulfide linkage were obtained. 